\title{
Effectiveness of management
} interventions for control of invasive Common ragweed Ambrosia artemisiifolia: a systematic review protocol

\author{
Stefan Schindler ${ }^{1,2^{*}}$, Helen R. Bayliss ${ }^{3}$, Franz Essl ${ }^{1,2}$, Wolfgang Rabitsch ${ }^{1}$, Swen Follak ${ }^{4}$ and Andrew S. Pullin ${ }^{3}$
}

\begin{abstract}
Background: Alien species are severely impacting the environment, public health and socioeconomy at a global scale. Their management is thus of crucial importance and the subject of intensive research efforts. Common ragweed Ambrosia artemisiifolia $\mathrm{L}$. is an alien species with negative impacts on agriculture, human health and biodiversity. It is a highly allergenic, wind-pollinated herb native to North America that was first introduced to Europe during the seventeenth century. It has since become widespread and is currently in an ongoing phase of rapid spread and increasing abundance. Several management approaches are currently implemented and effective control of the species can have strong socioeconomic benefits. However, evidence for management effectiveness is scattered and has not yet been synthesised systematically. For these reasons, we here aim to systematically review the evidence to assess (a) what is the effectiveness of management options used for control of Common ragweed Ambrosia artemisiifolia and (b) what is the effect of confounding factors such as habitat, climate and frequency and timing of treatment?

Methods: This protocol specifies the methods for conducting a systematic review to answer the specified questions. Search terms relating to the population and the intervention (type of management) will be combined and searched in a range of databases and other sources. Specific inclusion criteria are (i) any population of Ambrosia artemisiifolia at any habitat including populations in agricultural settings and such used for experimental research at any geographic location (including its native range), (ii) any physical, chemical, biological or combined management action; (iii) direct outcome measures including change in coverage, abundance, biomass, survival, reoccurrence, biology (e.g. growth, height, leaf area) or pollen production. The wide range of quality of primary literature will be evaluated with a tailored system for assessing susceptibility to bias and the reliability of the studies. If extracted data are suitable for quantitative synthesis, we aim to calculate effect sizes and conduct meta-analyses.
\end{abstract}

Keywords: Alien plant, Allergen, Asteraceae, biological invasions, Biological control, Chemical management, Invasive plant, Invasive species, Physical management, Public health

\section{Background}

Alien species are a global challenge and cause multiple environmental and socio-economic impacts [1-8]. Recent estimates for the EU amount to annually at least $€ 12$ billion damage by alien species [9]. The magnitudes

\footnotetext{
*Correspondence: stefan.schindler@umweltbundesamt.at

1 Department of Biodiversity and Nature Conservation, Environment

Agency Austria, Spittelauer Lände 5, 1090 Vienna, Austria

Full list of author information is available at the end of the article
}

of alien species introductions and of their impacts are increasing rapidly $[10,11]$ and expected to further increase due to globalization and climate change [12-14].

Common ragweed Ambrosia artemisiifolia L. is an alien species with negative impacts on agriculture, human health and biodiversity [15-20]. It is a highly allergenic, wind-pollinated herb with an annual life cycle. It is native to parts of North America and was first introduced to Europe in botanical gardens and in the wild during the 
seventeenth and eighteenth centuries $[18,19]$. Only rare introductions occurred in Europe until 1930, incipient spread and local naturalization happened between 1930 and 1960, followed by increased spread and emergence of large populations in the wild until 1990 and further spread and increasing abundances since then [19]. Spread is strongly favoured by the species' biology, mainly high numbers of seeds and the quick and efficient seed dispersal by human means [19-22]. Ambrosia artemisiifolia is a competitive weed in spring-sown crops. Impacts can amount to $10-50 \%$ and under special circumstances to $80 \%$ of yield loss [18-20,23, 24]. Human health impacts are related to $A$. artemisiifolia being a primary cause of pollen allergy in its native and alien ranges $[19,20,25-$ 27]. In Europe, its pollen shows increasing prevalence of sensitization [28]. Although biodiversity impacts of A. artemisiifolia are supposed to be low and qualify in Europe as 'no impact' according to the impact assessment scheme of Blackburn et al. [5], the species occasionally colonizes habitats of high conservation value such as dry grasslands, tall herb communities and open forests [18, 19].

An understanding of the effectiveness of Ambrosia artemisiifolia management can have strong socioeconomic benefits and is crucial for informing effective future policies on environmental management and public health [29]. However, efficiency, costs and benefits strongly depend on the effectiveness of the applied management. Attempted control of Ambrosia artemisiifolia has employed a range of physical, chemical and biological management techniques [19] that might also be combined. Ambrosia artemisiifolia tolerates substantial physical damage such as removal of the stem apex and leaves, because the plants regenerate from buds from the base or increase growth of existing lateral stems [30-33]. Cutting of vegetative plants is reported to delay the initiation of flowering but does not prevent reproduction [31], whereas hand pulling is reported to be most effective but very laborious [34, 35]. Mowing is commonly applied, but studies have found it efficient only if cutting was done as close to the soil surface as possible [34] and under particular timing [36]. Tillage may kill $A$. artemisiifolia plants and reduce their densities [37]. Emerging physical management techniques include crop rotation, thermal treatments and establishment of closed vegetation in combination with mowing [19]. Several options for chemical management with herbicides exist, in particular for the control of A. artemisiifolia on arable land [19]. Biological control has been implemented in the native range [38, 39] in Europe [40], Australia [41] and Asia [42]. Biological control agents used to date include the noctuid moth Tarachidia candefacta Huebner, the leaf beetles Zygogramma suturalis F. and Ophraella communa, and the pathogen Pustula tragopogonis (Pers.) Thines (synonym Albugo tragopogonis (D.C.) Gray) (Oomycota: Albuginaceae) [19].

\section{Objective of the review}

The aim of this review is to identify and synthesize available evidence on the effectiveness of management for control of Ambrosia artemisiifolia.

\section{Primary question}

What is the effectiveness of management options used for control of Common ragweed Ambrosia artemisiifolia?

The question consists of the following components (see study inclusion criteria for detailed definitions):

Population Common ragweed Ambrosia artemisiifolia. Intervention Any physical, chemical or biological management intervention.

Comparator Any relevant, e.g. temporal or spatial control or different application frequency and timing.

Outcome Any demonstrating a direct impact of management (or no impact) on Ambrosia artemisiifolia populations.

\section{Secondary question}

What are the effects on ragweed control effectiveness of factors such as habitat, climate and frequency and timing of treatment?

\section{Methods}

\section{Search strategy}

The aim of the search is to undertake a comprehensive survey of the available literature on the effectiveness of Ambrosia artemisiifolia management. Terms relating to the population and the intervention (type of management) will be combined and searched in a range of databases and other sources to maximise the relevant results returned. All searches, sources, dates and the number of hits retrieved will be recorded for inclusion in the final systematic review report appendices and the results of searches exported into reference management software to facilitate review management wherever possible.

\section{Search terms}

All database searches will be conducted in the English language. Potentially relevant non-English language articles will be recorded in an appendix, and may be included in the final systematic review if resources allow. Searches will be conducted using a combination of the species name and specific intervention and outcome keywords that have been refined by test searches in Thomson Reuters Web of Science (WoS; search function "TOPIC" searching titles, abstracts and keywords) in the following way 
(cf. Additional file 1): (i) three synonyms of the species name (i.e. Ambrosia artemisiifolia", "common ragweed" and "Ambrosia elatior") were complemented with the treatment terms "management" and "control", (ii) further 40 specific terms for treatments were added all together and (iii) tested one by one. At each steps the additional hits and their relevance for the review topic were assessed by checking the abstracts of all or a sample of them. Finally, we added, in a stepwise forward procedure, more and more treatment terms ordered by their relevance until no new relevant hits could be obtained (Additional file 1). The following search string was thus obtained and assessed regarding its comprehensiveness (see below section "Search comprehensiveness assessment"). While it was directly applied in WoS, it was slightly modified for some of the other databases (Additional file 1):

\section{Proposed search terms}

("Ambrosia artemisiifolia" OR "common ragweed" OR "Ambrosia elatior") AND ("manage" OR "control" OR "Ophraella" OR "leaf beetle*" OR "herbicid"” OR "damag"” OR "till" OR "natural enem*" OR "Zygogramma" OR "Lolium" OR "crop rotat" OR "remov"* OR "mow"

\section{Databases}

The following literature databases will be searched using the terms above to identify studies relevant to the question:

- Web of Science: http://wokinfo.com/.

- SCOPUS: http://www.scopus.com/.

- MEDLINE: https://www.nlm.nih.gov/bsd/pmresources. html.

- $C A B$ Direct including $C A B$ Abstracts and Global Health: http://www.cabdirect.org/.

- AGRICOLA: http://www.proquest.com/products-services/agricola-set-c.html.

- ProQuest Dissertations and Theses.

- OpenGrey: www.opengrey.eu.

\section{Search engines}

The general key words identified above will be entered into the advanced search function of Google Scholar (http://www.scholar.google.com) and zanran.com and the first 100 hits from each exported for assessment against the inclusion criteria. This will provide a further comprehensiveness check to test if any sections of the literature are missed by the main search.

\section{Specialist sources}

The results or publications web pages will be searched to identify relevant materials produced under the following European projects:
- HALT AMBROSIA http://www.halt-ambrosia.de.

- SMARTER (http://www.ragweed.eu)—others?

Further relevant studies will be searched for in the following specialist sources:

- Global Invasive Species Database (GISD): http:// www.issg.org/database/welcome.

- CABI Invasive Species Compendium: http://www. cabi.org/isc.

- European and Mediterranean Plant Protection Organization (EPPO): http://www.eppo.int/.

- Global Compendium of Weeds (GCW): http://www. hear.org/gcw/.

All issues of the following journals will also be searched online for relevant articles as there are currently not indexed in the databases:

- NeoBiota: http://neobiota.pensoft.net/.

- Management of Biological Invasions: http://www. reabic.net/journals/mbi/.

- BioInvasion Records: http://www.reabic.net/journals/bir/.

Early view articles and the three most recent issues of the following journal will also be searched online for relevant articles:

- Biological Invasions: http://www.springer.com/ life+sciences/ecology/journal/10530.

- Invasive Plant Science and Management: http://www. bioone.org/loi/ipsm.

- Weed Biology and Management: http://onlinelibrary. wiley.com/journal/10.1111/(ISSN)1445-6664.

- Weed Research: http://onlinelibrary.wiley.com/journal/10.1111/(ISSN)1365-3180.

- Weed Science: http://wssajournals.org/loi/wees.

- Weed Technology: http://wssajournals.org/loi/wete.

\section{Supplementary searches}

The reference lists of retrieved review articles will be checked to ensure that any relevant articles are captured and included into the search record.

\section{Search comprehensiveness assessment}

The comprehensiveness of the searches was tested by running Web of Science searches with the search terms identified during scoping and then checking the results compared to 52 references in the management section of the recent review on Ambrosia artemisiifolia by Essl et al. [19]. Both search strings, the complex one with the full list of 40 specific treatment terms 
as well as the proposed simpler one with 12 specific treatment terms (Additional file 1) yielded 29 of the 52 papers (Additional file 2). The 23 articles undetected by the searches mostly matched the inclusion criteria and included nine journals publications (e.g. [43-45]), five reports (e.g. [18, 37] including one EU regulation [46]), three conference papers [47-49] and two Ph.D. thesis $[31,50]$ not indexed by Web of Science. They further included three articles [41, 51, 52], that were indexed and relevant, but missed by the search string, because Ambrosia artemisiifolia was only one of many weed species studied and not prominently mentioned in title, abstract or keywords (Additional file 2). Assessing which of these 23 articles could be detected by our search string in the other literature databases, we detected 18 out of 23 articles, seven with Scopus secondary, four with CABI Direct and fourteen with Google Scholar. Scopus, Medline, ProQuest (Agricola; Dissertations and Theses) and OpenGrey did not yield any hits $(\mathrm{n}=0$ out of 23$)$. With the applied means, we could not detect five articles, i.e. one German Ph.D. thesis [31], the mentioned EU regulation [46], a 45 year old Russian conference paper [47], a short chapter published in an American hand book [53] and a report in Hungarian language [54] (Additional file 2). We conclude from this comprehensiveness assessment that the shorter search string would perform equally as the long one in terms of comprehensiveness, that Scopus Secondary and CABI Direct are complementary to Web of Science and that google scholar will have an important role to detect relevant papers that were not covered by the searches in the other literature databases. Retrieving papers dealing with multiple weed species must partly rely on snowballing, because inclusion of general search terms such as "weed" cause too many hits which are not relevant for this review (Additional file 1).

\section{Study inclusion criteria}

All studies retrieved by the searches will be assessed at title, abstract and full text (as appropriate) against the following study inclusion criteria to ensure that only relevant articles are admitted to the systematic review. A subset of 100 studies or $10 \%$ of the total results retrieved by the searches (whichever is highest) will be checked against the inclusion criteria at title and abstract by two independent reviewers and a kappa test used to determine agreement, with 0.6 or above indicating substantial agreement. Any disagreements will be discussed and any definitions that require clarifying will be adjusted accordingly. Studies will be included in the systematic review database if they meet the following inclusion criteria:
Population Any population of Common ragweed Ambrosia artemisiifolia in any habitat including populations in agricultural settings and such used for experimental research (e.g. in greenhouses) at any geographic location.

Intervention Any physical (e.g. hand pulling, mowing, tillage), chemical (e.g. herbicide application), biological or combined weed management treatment, excluding preventive pathway management (e.g. physical pathway management [19]).

Comparator No treatment or an alternative treatment. Outcomes Only direct outcome measures will be considered, including impact on ecological, biological and phytosociological parameters of Ambrosia artemisiifolia such as coverage, abundance, survival, reoccurrence, growth rate, height, leaf area, biomass accumulation, as well as pollen and seed production.

Types of study Studies applying Before-After-ControlImpact (BACI), before/after or treatment/control designs as well as studies that compare differing intensities of management (e.g. particular kinds of physical management, type or concentration of herbicide) or different application frequencies and timings (e.g. in cutting regimes). Any study providing suitable data for both intervention and comparator (including details on intensity and frequency of application) for an outcome of interest.

Studies excluded at full text will be recorded and provided as supplementary material along with reasons for exclusion.

We will not consider in this review data or articles that relate management of Ambrosia artemisiifolia to changes in outcome measures that are not directly related to the focal species such as agricultural yield, biodiversity and public health, but we acknowledge that such management effects can be relevant and should be considered when developing management and control strategies, alongside with the direct costs of the management [18, 19]. Although we acknowledge the importance of pathway management [55], we neither include in this review preventive measures which are dealing with introduction pathways, because they are of very different nature for typically consisting of policies related to trade restrictions [55]. Evidence for effectiveness of pathway management, relies on totally different kind of literature and would require a different set of search terms. In this context, we further exclude particular physical management operations, when they are related to pathway management $[19,35]$. Consistent with the Guidelines of the Collaboration for Environmental Evidence [56] we will provide a supplementary file listing all articles excluded at full text together with reasons for exclusion. 


\section{Study quality assessment}

Study quality assessment is required to group studies according to their quality and to add quality covariates to the analyses. Reviewers will conduct study quality assessment in all articles that fully match the inclusion criteria. Study quality will be scored following a hierarchy of evidence based on susceptibility to bias [57-59]. Each criterion (Table 1) will be scored by the reviewer, and complemented by a short text specifying the reasons for the scoring. For example, a study design with spatial and temporal control such as the BACI (Before/After/Control/ Impact) type [60] would be of higher quality than a simpler one relying only one spatial but not temporal control. The maximum overall score will equal 100 points (Table 1). For studies assessing the management efficiency of several management options, the scoring might be different for each conducted analysis, because sampling effort might vary across considered taxa or some of the primary analyses and results may be presented incompletely. The particular system developed for the purpose of this review considers the features recommended by Bilotta et al. [61] and was adapted from the quality assessment system developed by Schindler et al. [62]; it will be based on an evaluation of the following criteria (cf. Table 1):

i. Study design and repetitions: the study design determines the study results susceptibility to bias, robustness, explanatory power and generalizability. Scoring will follow a scheme that considers study design expressed in temporal and spatial repetitions.

ii. Appropriateness of methodology, and spatial and temporal coverage: appropriate sampling methods and statistical approaches are required to make best and unbiased use of information gathered. Validity and relevance of study results depends on the appropriateness of methods used and on the appropriate coverage in terms of the spatial and temporal scale of the study.

iii. Intervention, intra-treatment variation, and confounding factors: interventions might be badly specified or many different measures might be treated as interventions' and compared to control sites. Other confounding factors might lead to the conclusion that the study results might be prone to bias or error.

iv. Baseline comparison: studies might be confounded in terms of the baseline case selected, because the control sites are too different in regards their ecology or because they had been sampled at a large spatial or temporal distance or even with a different sampling protocol compared to the sampling units subject to interventions.

v. Bias linked to clarity and publication: the rigor that was implemented during all the stages of a primary study remains uncertain for the reviewer. However, clarity and thoroughness of the presentation of meth- ods and results might indicate overall scientific rigor and reduce the probability of wrong interpretations by the reviewer [63]. Errors might occur during all stages of a study and confounding statements or very unreliable results in tables and figures that are not mentioned in the text or explained in the discussion, might indicate flaws in data processing or reasoning. Missing results for specific cases can lead to directional bias, for instance when only significant results are reported [64].

\section{Data extraction strategy}

Data allowing the estimation of effect sizes will be extracted into a purpose built spreadsheet by one reviewer and checked for consistency and accuracy by a second. A single article can contain several cases of valid and relevant analyses and all of them will be extracted in different spreadsheet rows. Data to be extracted will include the intervention and its intensity (dose, frequency of application), the outcomes, the methodology and other potentially confounding factors that have been identified as possible reasons for heterogeneity in the primary studies.

Data extraction forms will be piloted on a representative sample of the articles, to represent the range of articles available, and amended if necessary to improve repeatability and efficiency. For most study designs, we expect to extract raw data (means, standard deviations sampling sizes) as well as F values, $\mathrm{p}$-values, sample sizes and degrees of freedom. Special care will be taken regarding potential publication bias that occurs when only significant results are sufficiently presented in a paper that contains several kinds of analyses, for instance related to different kinds or intensities of treatments.

Missing data for the most important issues (e.g. statistics, sample sizes, degrees of freedom) will be calculated or inferred where possible from raw data or summary statistics presented: if not possible the authors will be contacted. Missing data regarding some of the covariates (altitude, years of data collection, etc.) will be researched, if considered as relevant for the particular case.

\section{Potential effect modifiers and reasons for heterogeneity}

The following effect modifiers and reasons for heterogeneity will be extracted:

- General study parameters: country, longitude, latitude, altitude, geographic zone, biogeographic realm, biome [65], Köppen-Geiger climate classes [66], investigated environment (artificial surfaces, agricultural areas, forests, wetlands, mixed and others), habitat type, years of data collection, spatial extent of the study area, naturalness of the study area [67]; 


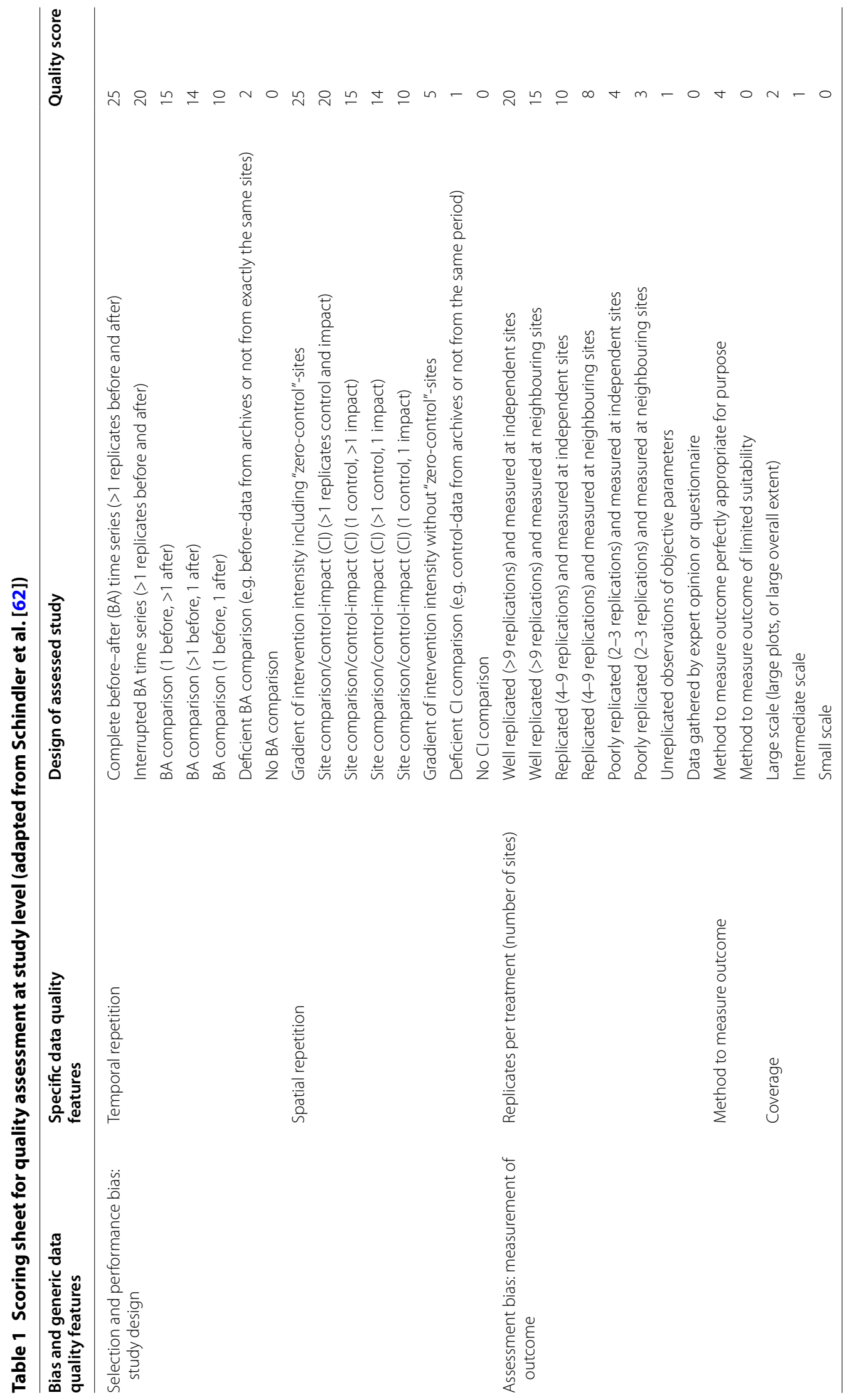




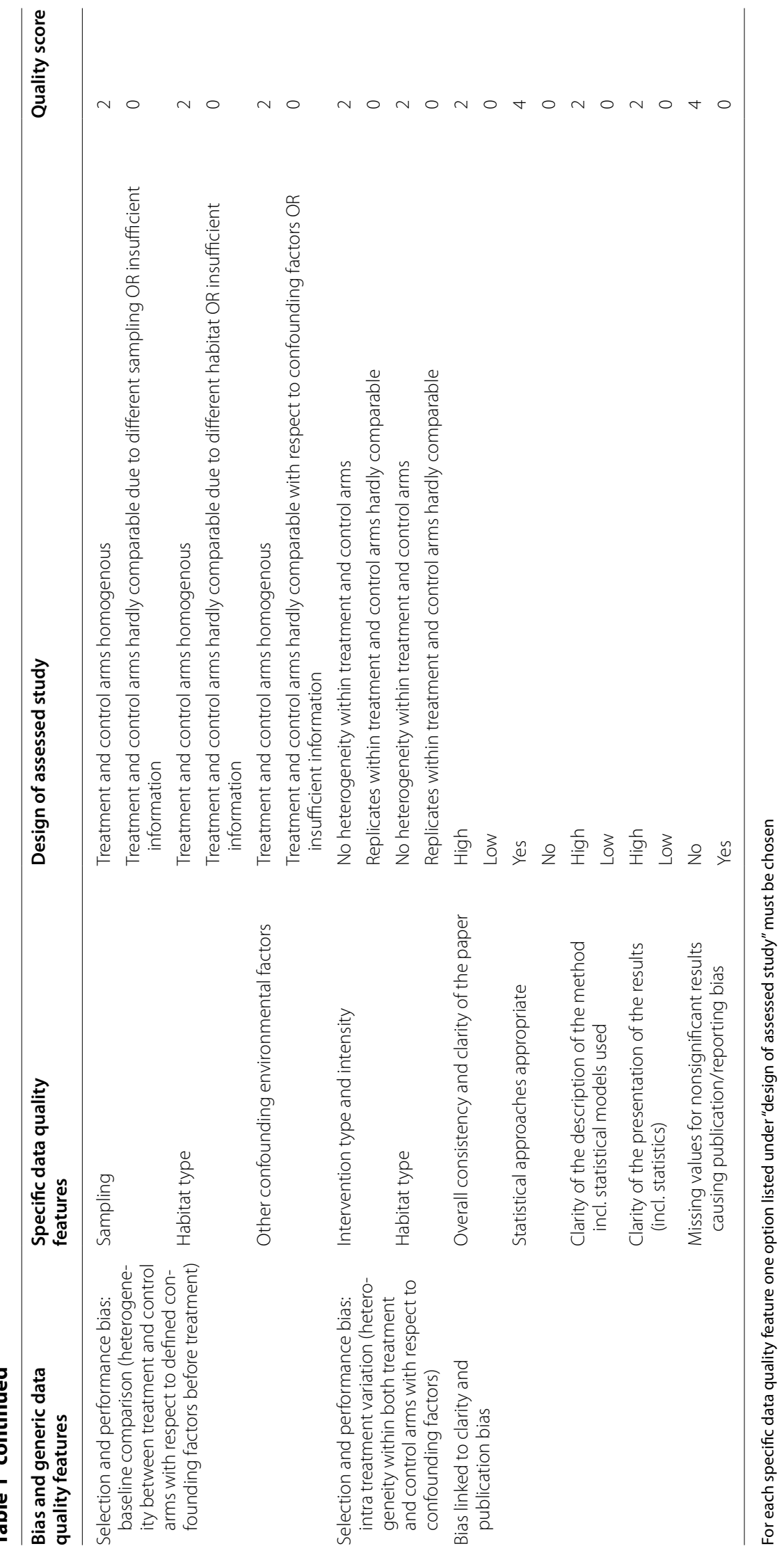


- Methodological variables: the kind of intervention, method of application, time since implementation of the treatment (e.g. length of time since biological control agent released), length, intensity and/or frequency of treatment, specific weather conditions after application of the treatment, type of control, study design (cf. Table 1), number of replicates of plots per sampling site, sampling method, outcome measure used (see above), statistical method applied.

\section{Data analysis, synthesis and presentation}

The extracted study cases will be grouped into hierarchical categories by intervention, also considering types of comparators, time since intervention and study quality. Whereas the first level category for interventions will be physical, chemical, biological and combined (i.e. application of $>1$ of the other three) treatment, the exact categories will depend on the quality and type of data retrieved during the data extraction stage. The analyses will focus on the differences in effect size among the four major types of interventions, i.e. physical, chemical biological and combined control. Additionally, we will test for the effects of the main covariates such as time since intervention, and habitat investigated.

If the extracted data are suitable for quantitative synthesis, we aim to calculate effect sizes based on standardised mean differences (if the units differ across studies) and carry out meta-analyses [68]. Sensitivity analyses will be run to explore the effects of including studies with different designs and methodological quality. If possible, tests for publication bias will be conducted. Outcomes from this review will be discussed with selected stakeholders and implications for environmental management policies considered.

\section{Additional files}

Additional file 1. Search string development in web of science (November 2015).

Additional file 2. Search comprehensiveness assessment.

\section{Authors' contributions}

$\mathrm{SS}$ and $\mathrm{HB}$ drafted the protocol with input from the other authors. All authors read and approved the final manuscript.

\section{Author details \\ ${ }^{1}$ Department of Biodiversity and Nature Conservation, Environment Agency Austria, Spittelauer Lände 5, 1090 Vienna, Austria. ${ }^{2}$ Division of Conservation Biology, Vegetation and Landscape Ecology, University of Vienna, Rennweg 14, 1030 Vienna, Austria. ${ }^{3}$ Centre for Evidence-Based Conservation, School of the Environment, Natural Resources and Geography, Bangor University, Bangor LL57 2UW, UK. ${ }^{4}$ Austrian Agency for Health and Food Safety, Institute for Sustainable Plant Production, Spargelfeldstraße 191, 1220 Vienna, Austria.}

\section{Acknowledgements}

We thank Hans-Peter Hutter, Ivana Milakovic and Mildren Adam as well as three referees for their very helpful suggestions.

\section{Competing interests}

The authors declare that they have no competing interests.

\section{Sources of support}

This project is funded under the Austrian Climate and Energy Fund within the framework of the "ACRP" Program (Project Number KR13AC6K11141).

Received: 26 November 2015 Accepted: 7 May 2016

Published online: 06 June 2016

References

1. Pimentel D, Lach L, Zuniga R, Morrison D. Environmental and economic costs of nonindigenous species in the United States. Bioscience. 2000;50:53-65.

2. Pimentel D. Biological invasions: economic and environmental costs of alien plant, animal, and microbe species. Boca Raton: CRC Press; 2002.

3. Gren IM, Isacs L, Carlsson M. Costs of alien invasive species in Sweden. Ambio. 2009:38(3):135-40.

4. Vilà M, Espinar JL, Hejda M, Hulme PE, Jarošík V, Maron JL, et al. Ecological impacts of invasive alien plants: a meta-analysis of their effects on species, communities and ecosystems. Ecol Lett. 2011;14:702-8.

5. Blackburn TM, EssI F, Evans T, Hulme PE, Jeschke JM, Kühn I, et al. A unified classification of alien species based on the magnitude of their environmental impacts. PLoS Biol. 2014;12:e1001850.

6. Capinha C, Essl F, Seebens H, Moser D, Pereira HM. The dispersal of alien species redefines biogeography in the Anthropocene. Science. 2015:348:1248-51.

7. Van Kleunen M, Dawson W, Essl F, Pergl J, Winter M, Weber E, et al. Global exchange and accumulation of non-native plants. Nature. 2015;525:100-3.

8. Schindler S, Staska B, Adam M, Rabitsch W, Essl F. Alien species and public health impacts in Europe: a literature review. NeoBiota. 2015;27:1.

9. EC (European Commission). The mid-term review of the EU biodiversity strategy to 2020. Brussels. COM(2015)478.

10. Simberloff D, Martin JL, Genovesi P, Maris V, Wardle DA, Aronson J, et al. Impacts of biological invasions: what's what and the way forward. Trends Ecol Evol. 2013;28:58-66.

11. Tittensor DP, Walpole M, Hill SLL, Boyce DG, Britten GL, Burgess ND, et al. A mid -term analysis of progress towards international biodiversity targets. Science. 2014:346:241-4.

12. Essl F, Dullinger $S$, Rabitsch W, Hulme PE, Hülber K, Jarosik V, et al. Socioeconomic legacy yields an invasion debt. Proc Nat Acad Sci. 2011;108:203-7.

13. Caminade C, Medlock JM, Ducheyne E, McIntyre KM, Leach S, Baylis M, Morse AP. Suitability of European climate for the Asian tiger mosquito Aedes albopictus: recent trends and future scenarios. J R Soc Interface. 2012;9:2708-17.

14. Dobson A, Barker K, Taylor SL. Biosecurity. The socio-politics of invasive species and infectious diseases. Oxon (NY): Earthscan, Routledge; 2013.

15. EssI F, Dullinger S, Kleinbauer I. Changes in the spatio-temporal patterns and habitat preferences of Ambrosia artemisiifolia during its invasion of Austria. Preslia. 2009;81:119-33.

16. Vilà M, Basnou C, Pyšek P, Josefsson M, Genovesi P, Gollasch S, et al. How well do we understand the impacts of alien species on ecosystem services? A pan-European, cross-taxa assessment. Front Ecol Env. 2010;8:135-44

17. Ziska LH, Knowlton K, Rogers C, Dalan D, Tierney N, Elder MA, et al. Recent warming by latitude associated with increased length of ragweed pollen season in central North America. Proc Nat Acad Sci. 2011;108:4248-51.

18. Bullock J, Chapman D, Schaffer S, Roy D, Girardello M, Haynes T, et al. Assessing and controlling the spread and the effects of common ragweed in Europe. Report no ENV.B2/ETU/2010/0037. European Commission; 2012.

19. Essl F, Biró K, Brandes D, Broennimann O, Bullock JM, Chapman DS, et al. Biological Flora of the British Isles: Ambrosia artemisiifolia. J Ecol. 2015:103:1069-98.

20. Baker R, Caffier D, Choiseul JW, De Clercq P, Simon ED, Gerowitt B, et al. Opinion of the Scientific Panel on plant health on a request from the 
commission on the pest risk assessment made by Poland on Ambrosia spp. EFSA J. 2007:528;1-32. doi:10.2903/j.efsa.2007.528.

21. Brandes D, Nitzsche J. Verbreitung, Ökologie und Soziologie von Ambrosia artemisiifolia L. in Mitteleuropa. Tuexenia. 2007;27:167-94.

22. Fumanal B, Chauvel B, Bretagnolle F. Estimation of pollen and seed production of common ragweed in France. Ann Agri Env Med. 2007;14:233-6.

23. Weaver SE. Impact of lamb's-quarters, common ragweed and green foxtail on yield of maize and soybean in Ontario. Can J Plant Sci. 2001;81:821-8.

24. Cowbrough MJ, Brown RB, Tardif FJ. Impact of common ragweed (Ambrosia artemisiifolia) aggregation on economic thresholds in soybean. Weed Sci. 2003;51:947-54.

25. White JF, Bernstein DI. Key pollen allergens in North America. Ann Allergy Asthma Immunol. 2003;91:425-35.

26. Burbach GJ, Heinzerling LM, Edenharter G, Bachert C, Bindslev-Jensen C, Bonini S, et al. GA2LEN skin test study II: clinical relevance of inhalant allergen sensitizations in Europe. Allergy. 2009;64:1507-15.

27. Smith M, Cecchi L, Skjøth CA, Karrer G, Śikoparija B. Common ragweed: a threat to environmental health in Europe. Environ Int. 2013;61:115-26.

28. Burbach GJ, Heinzerling LM, Rohnelt C, Bergmann KC, Behrendt H, Zuberbier T. Ragweed sensitization in Europe-GA(2)LEN study suggests increasing prevalence. Allergy. 2009;64:664-5.

29. Richter R, Berger U, Dullinger S, Essl F, Vogl G. Spread of invasive ragweed: climate change, management and how to reduce allergy costs. J Appl Ecol. 2013;50:1422-30.

30. Irwin DL, Aarssen LW. Testing for cost of apical dominance in vegetation: a field study of three species. Ann Bot Fenn. 1996;33:123-8.

31. Nitzsche J. Ambrosia artemisiifolia L. (Beifuß-Ambrosie) in Deutschland. Biologie der Art, Konkurrenzverhalten und Monitoring. Ph.D. thesis. Braunschweig, Germany: University of Braunschweig; 2010.

32. Simard MJ, Benoit DL. Distribution and abundance of an allergenic weed, common ragweed (Ambrosia artemisiifolia L.), in rural settings of southern Québec, Canada. Can. J Plant Sci. 2010;90:549-57.

33. Patracchini C, Vidotto F, Ferrero A. Common ragweed (Ambrosia artemisiifolia) growth as affected by plant density and clipping. Weed Tech. 2011;25:268-76.

34. Bohren C, Mermillod G, Delabays N. Common ragweed (Ambrosia artemisiifolia L.) in Switzerland: development of a nationwide concerted action. J Plant Dis Protect. 2006;XX:497-503.

35. Karrer G, Milakovic M, Kropf M, Hackl G, Essl F, Hauser M, et al. Ausbreitungsbiologie und Management einer extrem allergenen, eingeschleppten Pflanze-Wege und Ursachen der Ausbreitung von Ragweed (Ambrosia artemisiifolia) sowie Möglichkeiten seiner Bekämpfung. Final Report. Vienna (Austria): BMLFUW; 2011.

36. Milakovic I, Fiedler K, Karrer G. Management of roadside populations of invasive Ambrosia artemisiifolia by mowing. Weed Res. 2014;54:256-64.

37. Buttenschøn RM, Waldispühl S, Bohren C. Guidelines for management of common ragweed, Ambrosia artemisiifolia. EUPHRESCO project AMBROSIA 2008-09. 2009. http://http://ragweed.eu/guidelines-for-management-of-common-ragweed-ambrosia-artemisiifolia-euphresco-2009. Accessed 20 Oct 2015.

38. Cartwright RD, Templeton GE. Biological limitations of Protomyces gravidus as a mycoherbicide for giant ragweed. Ambrosia trifida. Plant Dis. 1988;72:580-2.

39. Teshler MP, DiTommaso A, Gagnon JA, Watson AK. Ambrosia artemisiifolia L., common ragweed (Asteraceae). In: Huber JT, editor. Biological Control Programmes in Canada. New York (NY): CABI Publishing; 2002. p. 290-4.

40. Gerber E, Schaffner U, Gassmann A, Hinz HL, Seier M, Müller-Schärer H. Prospects for biological control of Ambrosia artemisiifolia in Europe: learning from the past. Weed Res. 2011;51:559-73.

41. Palmer WA, Heard T, Sheppard AW. A review of Australian classical biological control of weeds programs and research activities over the past 12 years. Biol Control. 2010;52:271-87.

42. Zhou ZS, Guo JY, Chen HS, Wan FH. Effects of temperature on survival, development, longevity, and fecundity of Ophraella communa (Coleoptera: chrysomelidae), a potential biological control agent against Ambrosia artemisiifolia (Asterales: Asteraceae). Physiol Ecol. 2010;39:1021-7.

43. Béres I. Integrated weed management strategies of Ambrosia artemisiifolia. Magyar Gyomkutatás és Technológia. 2004;1:3-14.
44. Kazinczi G, Béres I, Novák R, Biró K, Pathy Z. Common Ragweed (Ambrosia artemisiifolia). A review with special regards to the results in Hungary. III. Resistant biotopy, control methods and authority arrangements. Herbologia. 2008;9:119-44.

45. Kukorelli G, Reisinger P, Torma M, Adamszki T. Experiments with the control of common ragweed in imidazolinone-resistant and tribenuronmethyl-resistant sunflower. Herbologia. 2011;12:15-22.

46. EU (European Union). Commission Regulation (EU) No 744/2012 of 16 August 2012 amending Annexes I and II to Directive 2002/32/EC of the European Parliament and of the Council as regards maximum levels for arsenic, fluorine, lead, mercury, endosulfan, dioxins, Ambrosia spp., diclazuril and lasalocid A sodium and action thresholds for dioxins. Off J Eur Union 2012;L219:5-12.

47. Kovalev OV. Modern outlooks of biological control of weed plants in the USSR and the international phytophagous exchange. In: Dunn PH, editor. Second International Symposium on Biological Control of Weeds, Rome, Italy. Slough: Commonwealth Agricultural Bureaux, Farnham Royal; 1971:166-72.

48. Reznik SY, Spasskaya IA, Dolgovskaya MY, Volkovitsh MG, Zaitzev VF. The ragweed leaf beetle Zygogramma suturalis F. (Coleoptera: Chrysomelidae) in Russia: current distribution, abundance and implication for biological control of common ragweed, Ambrosia artemisiifolia L. In: Julien MH, Sforza R, Bon MC, Evans HC, Hatcher PE, Hinz HE, Rector BG, editors. 7th International Symposium on Biological Control of Weeds. Wallingford: CAB International; 2007:614-9.

49. Karrer G, Pixner T. The contribution of post-harvest ripened ragweed seeds after cut for control. In: GEIB, editor. NEOBIOTA: Halting Biological Invasions in Europe: from Data to Decisions, 7th European Conference on Biological Invasions. León, Spain: GEIB; 2012:229.

50. Meiss H. Diversifying crop rotations with temporary grasslands: potentials for weed management and farmland biodiversity. Ph.D. thesis, Giessen, Germany: 2010.

51. Murphy SD, Clements DR, Belaoussoff S, Kevan PG, Swanton CJ. Promotion of weed species diversity and reduction of weed seedbanks with conservation tillage and crop rotation. Weed Sci. 2006;54:69-77.

52. Meiss H, Munier-Jolain N, Henriot F, Caneiil J. Effects of biomass, age and functional traits on regrowth of arable weeds after cutting. J Plant Dis Protect. 2008;21:493-500

53. Goeden RD, Andres LA. Three recent successes outside of North America. In: Fisher TW, editor. Handbook of biological control. San Diego: Academic Press; 1999. p. 884-5.

54. Kazinczi G, Novák R (editors). A Parlagfu visszaszorításának integrált módszerei (Integrated methods for suppression of ragweed). Budapest, Hungary: National Food Chain Safety Office, Directorate of Plant Protection, Soil Conservation and Agri-Environment; 2012.

55. Essl F, Bacher S, Blackburn TM, Booy O, Brundu G, Brunel S, et al. Crossing frontiers in tackling pathways of biological invasions. Bioscience. 2015:65:769-82.

56. Collaboration for environmental evidence. guidelines for systematic review and evidence synthesis in environmental management. Version 4.2. Environmental Evidence 2013. http://www.environmentalevidence. org/Documents/Guidelines/Guidelines4.2.pdf.

57. Stevens A, Milne R. The effectiveness revolution and public health. In: Scally G, editor. Progress in public health. London: Royal Society of Medicine Press; 1997. p. 197-225.

58. Pullin AS, Knight TM. Effectiveness in conservation practice: pointers from medicine and public health. Conserv Biol. 2001;15:50-4.

59. Rilov G, Mant R, Lyons D, Bulleri F, Benedetti-Cecchi L, Kotta J, et al. How strong is the effect of invasive ecosystem engineers on the distribution patterns of local species, the local and regional biodiversity and ecosystem functions? Environ Evid. 2012;1:10.

60. Smith EP. BACl design. In: El-Shaaraw AH, Piegorsch WW, editors. Encyclopedia of Environmetrics. Chichester: Wiley; 2002. p. 141-8.

61. Bilotta GS, Milner AM, Boyd IL. Quality assessment tools for evidence from environmental science. Environ Evid. 2014;3:14.

62. Schindler S, Kropik M, Euller K, Bunting SW, Schulz-Zunkel C, Hermann A, et al. Floodplain management in temperate regions: is multifunctionality enhancing biodiversity? Environ Evid. 2013;2:10.

63. Haddaway NR. A call for better reporting of conservation research data for use in meta-analyses. Conserv Biol. 2015;29:1242-5. 
64. Schafer JL. Analysis of incomplete multivariate data, 1st edn. Monographs on Statistics and Applied Probability, vol 72. Boca Raton: Chapman \& Hall; 1997.

65. Olson DM, Dinerstein E, Wikramanayake ED, Burgess ND, Powell GVN, Underwood EC, et al. Terrestrial ecoregions of the world: a new map of life on earth. Bioscience. 2001;51:933-8.
66. Rubel F, Kottek M. Observed and projected climate shifts 1901-2100 depicted by world maps of the Köppen-Geiger climate classification. Meteorol Z. 2010;19:135-41.

67. Machado A. An index of naturalness. J Nat Conserv. 2004;12:95-110.

68. Koricheva J, Gurevitch J, Mengersen K. Handbook of Meta-analysis in Ecology and Evolution. Princeton: Princeton University Press; 2013.

\section{Submit your next manuscript to BioMed Central} and we will help you at every step:

- We accept pre-submission inquiries

- Our selector tool helps you to find the most relevant journal

- We provide round the clock customer support

- Convenient online submission

- Thorough peer review

- Inclusion in PubMed and all major indexing services

- Maximum visibility for your research

Submit your manuscript at www.biomedcentral com/submit 